\title{
A (in)elegibilidade de trabalhadores encaminhados ao Programa de Reabilitação Profissional do INSS
}

\author{
Geovana de Souza Henrique dos Santos \\ Universidade Federal de São Carlos (UFSCar)
}

\author{
Roseli Esquerdo Lopes \\ Universidade Federal de São Carlos (UFSCar)
}

\begin{abstract}
A (in)elegibilidade de trabalhadores encaminhados ao Programa de Reabilitação Profissional do INSS

Resumo: Este estudo tem como objetivo investigar os motivos da não inclusão de trabalhadores contribuintes junto ao Programa de Reabilitação Profissional (PRP) do Instituto Nacional do Seguro Social, INSS. Lançando-se mão de um estudo de caso, transversal e documental, foram coletados dados dos prontuários dos sujeitos encaminhados ao PRP de uma Agência do INSS, da região Sudeste do Brasil, entre 2007 e 2012. Elaborou-se um instrumento para a referida coleta, para padronizar o registro dos dados, verificando-se nos pareceres finais acerca da Avaliação do Potencial Laborativo, redigidos pela equipe responsável pelo atendimento inicial, se o trabalhador encaminhado foi elegível ou não para integrar o PRP. Os motivos descritos pela equipe para a não inclusão dos trabalhadores foram agrupados segundo a proximidade quanto ao significado, formando categorias centrais, discriminando-se as justificativas de cada uma. Palavras-chave: Reabilitação Profissional. Previdência Social. Trabalho. Instituto Nacional do Seguro Social.
\end{abstract}

\section{The (In)Eligibility of Workers Sent to the INSS Professional Rehabilitation Program}

Abstract: The purpose of this study is to investigate the reasons to not accept workers who make contributions into the Professional Rehabilitation Program (PRP) of the National Social Security Institute (INSS). Using a transversal and documental case study, data were collected from the records individuals sent to the PRP at an INSS agency in southeastern Brazil, from 2007-2012. A tool developed to standardize the data collection and recording, verified if the final Evaluation of Work Potential reports prepared by the staff responsible for initial attendance determined if the worker sent was eligible or not to enter the PRP program. The reasons described by the staff for not including workers were grouped according to the proximity to a signifier, forming central categories, discriminating them by the justifications made in each case.

Keywords: Professional Rehabilitation. Social Security. Work. National Social Security Institute 


\section{Introdução}

Integrando uma pesquisa mais ampla que teve como principal objetivo compreender a contribuição do Programa de Reabilitação Profissional (PRP) de uma Agência da Previdência Social (APS), do Instituto Nacional do Seguro Social (INSS), na região Sudeste do Brasil, entre os anos de 2007 a 2012, na reinserção do trabalhador no mercado de trabalho, este estudo se volta para a investigação dos motivos que levaram a não inclusão de trabalhadores no PRP da referida Agência ${ }^{1}$. Foram coletados dados de prontuários de todos os usuários encaminhados ao PRP naquele período, verificando-se que menos da metade foi elegível.

O termo reabilitação profissional se consolidou na década de 1960, visto como "uma resposta pública à questão da incapacidade" (TAKAHASHI; IGUTI, 2008, p.2662). É uma opção do trabalhador, em sua maioria contribuinte da Previdência Social, em gozo de auxílio-doença acidentário ou previdenciário, que se encontra incapacitado para exercer seu trabalho de origem, cuja incapacidade e restrição laboral estejam estabilizadas e sejam de longa duração.

A reabilitação profissional é a assistência (re)educativa e de (re)adaptação profissional que visa proporcionar aos segurados, "incapacitados parcial ou totalmente para o trabalho, em caráter obrigatório, independentemente de carência, e às pessoas com deficiência, os meios indicados para o reingresso no mercado de trabalho e no contexto em que vivem" (BRASIL, 2010a).

A prestação dos serviços de reabilitação profissional pela Previdência Social no Brasil tem um duplo papel; primeiramente, é uma intervenção que busca reduzir e superar as desvantagens produzidas pelas incapacidades, mas, por outro lado, tem como função reduzir o tempo de concessão de benefícios previdenciários. Ainda é um direito constitucional que deve ser efetivado na prática (TAKAHASHI; IGUTI, 2008; MAENO; VILELA, 2010).

O encaminhamento ao PRP é realizado pela perícia médica do Instituto, e o atendimento pela equipe de reabilitação profissional, a qual deve ser, preferencialmente, multidisciplinar, composta por Peritos Médicos do INSS e Analistas do Seguro Social com formação nas áreas de Serviço Social, Psicologia, Terapia Ocupacional, Sociologia, Fisioterapia, ou áreas afins ao processo, denominados Responsável pela Orientação Profissional (ROP) (BRASIL, 2011).

Com o encaminhamento ao Programa, o primeiro atendimento envolve uma entrevista inicial que inclui a realização de uma perícia no setor de reabilitação profissional, para a Avaliação do Potencial Laborativo (APL) do usuário e definição, pela equipe, sobre sua elegibilidade para o Programa. Nessa avaliação, é preenchido o Formulário de Avaliação do Potencial Laborativo (FAPL), composto por duas partes, uma sob a responsabilidade do médico perito e a outra do ROP, seguidas pela elaboração da análise conjunta e de um laudo conclusivo, acerca da elegibilidade do usuário (BREGALDA; LOPES, 2011).

O laudo final dessa avaliação inclui uma parte aberta, em que os profissionais da equipe podem descrever o caso e justificar sua decisão e os motivos pelos quais, se for o caso, não incluíram o trabalhador no PRP. Na sequência, são disponibilizados códigos previdenciários que padronizam a decisão da equipe sobre a conclusão da avaliação. Neste estudo, foram analisados os motivos da inelegibilidade do trabalhador a partir do laudo descrito pela equipe, não tendo sido considerados os códigos previdenciários, por não descreverem as justificativas alegadas para a não inclusão do usuário para o PRP.

Caso o trabalhador não seja considerado elegível, o benefício previdenciário, na maioria das vezes, é cessado. Se for elegível, deverá se submeter ao PRP (BRASIL, 2010b) com a manutenção do benefício por mais tempo, até a conclusão do Programa. Este consiste no contato com a empresa de vínculo, para aqueles filiados ao INSS como empregados, solicitando-se a readaptação profissional. Sendo esta inviável ou se o usuário tiver outra forma de filiação, é disponibilizado um curso profissionalizante para promover a qualificação em outra área compatível, além de ser possível a oferta de próteses e órteses.

O final do processo reabilitatório se dá quando o usuário concluir, satisfatoriamente, o treinamento na empresa de vínculo ou o curso profissionalizante. É emitido um certificado homologando a reabilitação profissional, permitindo que os reabilitados concorram a vagas especiais para pessoas com deficiência ou reabilitadas nas empresas, cessando-se o benefício. Segundo Maeno, Takahashi e Lima (2009), as obrigações da Previdência encerram-se com a emissão do certificado de reabilitação, sem compromisso com os trabalhadores demitidos ou com aqueles que não forem acolhidos pela empresa.

\section{Procedimentos metodológicos e éticos}

Foi solicitada uma autorização ao gerente da instituição, responsável pela Agência pesquisada, para serem utilizados os dados dos processos dos usuários do Programa. Na solicitação, detalhou-se a proposta da 
pesquisa como um todo e foram descritos os procedimentos pretendidos; a coleta foi autorizada. A pesquisa foi submetida ao Comitê de Ética em Pesquisa da Universidade Federal de São Carlos (UFSCar), tendo sido aprovada pelo Parecer No $386.931 / 2013$.

A coleta de dados foi feita nos prontuários de trabalhadores encaminhados ao PRP no período de 2007 a 2012. O início em 2007 se deu por ter sido quando o arquivo ativo do Programa na Agência começou a ser organizado; o encerramento em 2012 deveu-se ao fato da coleta ter ocorrido em 2013 . O instrumento para reunir os dados desses prontuários, a fim de padronizá-los, foi elaborado tomando-se a literatura pertinente e, também, da experiência prática no campo.

Trata-se de um estudo transversal, com a coleta de dados realizada num momento único. Segundo Sampieri, Collado e Lucio (2006), este tipo de pesquisa visa descrever variáveis e analisar a sua incidência e inter-relação em certo momento, assim, a reunião dos dados ocorre em um tempo único, podendo englobar vários grupos, objetos ou indicadores, bem como diferentes situações.

Também é uma pesquisa documental, uma vez que foi utilizada como fonte de dados prontuários escritos, encerrados e arquivados no setor. De acordo com Lakatos e Marconi (2002) e Gil (1999), a pesquisa documental abrange documentos, escritos ou não, constituindo o que se denomina de fontes primárias. Como foi estudada uma única Agência da Previdência Social do INSS, de uma cidade, da região Sudeste no Brasil, configurou-se como um estudo de caso, com foco nos motivos da elegibilidade ou não de usuários encaminhados ao PRP.

Para fins de análise do material encontrado, os motivos descritos pela equipe para a não inclusão dos trabalhadores no Programa foram agrupados segundo a proximidade quanto ao significado, formando categorias centrais, discriminando-se as justificativas de cada uma.

\section{Resultados e discussão}

Após varredura manual e contagem de todos os prontuários dos trabalhadores encaminhados ao Programa, no período citado, foram encontrados 676 usuários encaminhados. Destes, foram selecionados 592, a partir dos critérios de exclusão, a saber: no momento da coleta, 27 ainda estavam em Programa e 57 foram encerrados após 31/12/12, totalizando 84 usuários.

Verificou-se que, dos 592 encaminhamentos, somente 300 pessoas $(50,68 \%)$ foram incluídas pela equipe no Programa; 264 (44,59\%) não foram consideradas elegíveis. Do restante, 26 (4,39\%) APLs não foram realizadas e, em duas delas $(0,34 \%)$ o trabalhador se recusou a cumprir o Programa.

\section{Figura 1: Pareceres da equipe descritos nos laudos conclusivos}

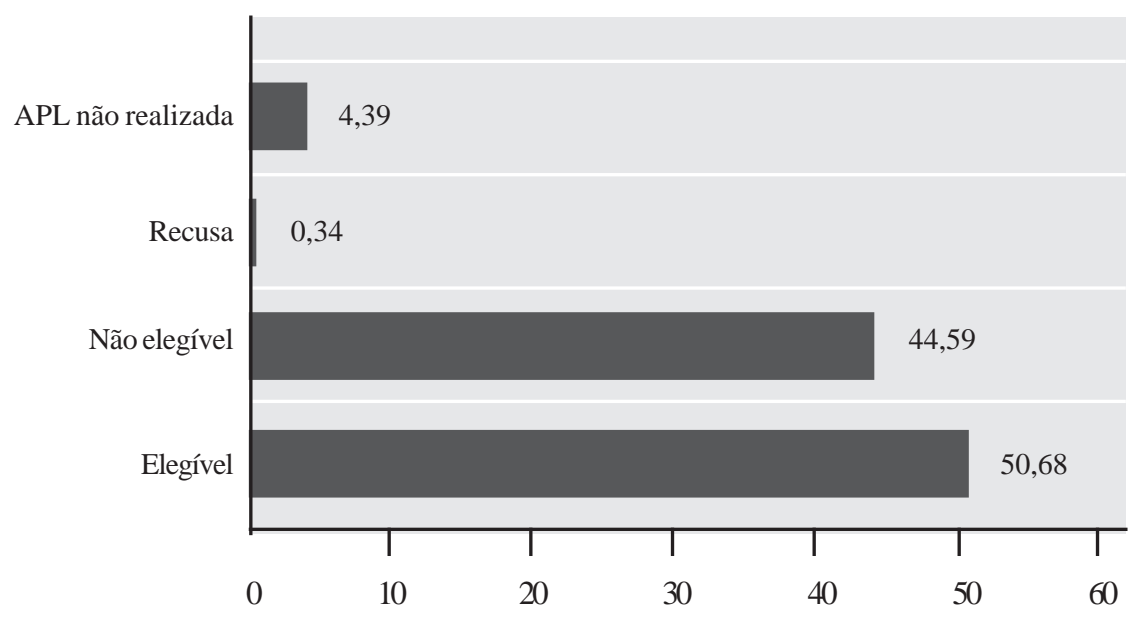

Fonte: Arquivos do Programa de Reabilitação Profissional. 
Foi observado que os motivos que levaram a não inclusão dos trabalhadores no Programa, se dividiram conforme exposto na Figura 2.

\section{Figura 2: Motivos para não inclusão do trabalhador no PRP}

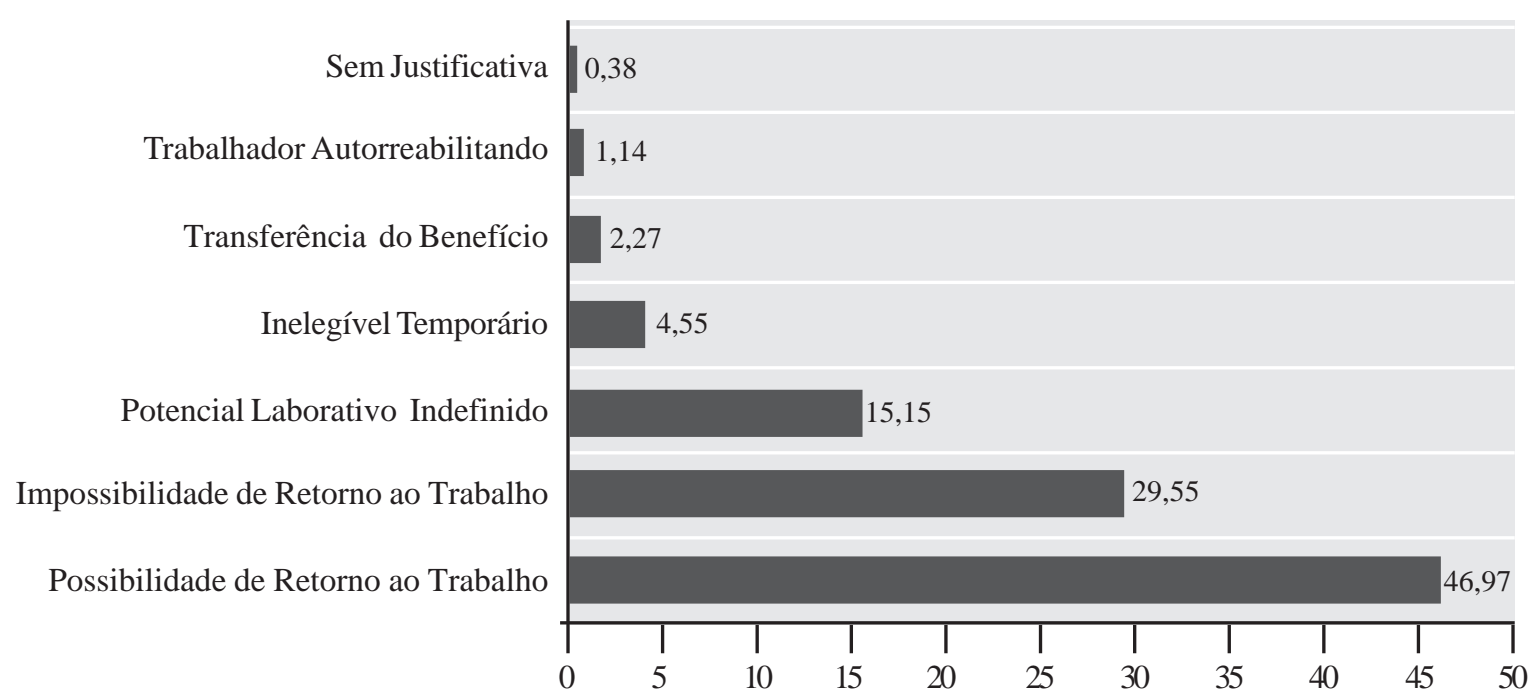

Fonte: Arquivos do Programa de Reabilitação Profissional.

Durante a APL não é previsto envolvimento algum do trabalhador na tomada de decisão sobre sua elegibilidade. Takahashi et al. (2010) destacam que, muitas vezes, é reservado ao trabalhador o papel de mero "fornecedor" das informações, para que os profissionais detectem o que é adequado ou inadequado nas condições de trabalho. Conforme as autoras, a presença e participação do trabalhador na definição do melhor caminho a seguir se mostrou positiva, sendo seu envolvimento e empoderamento no processo de reabilitação profissional essenciais no retorno ao trabalho.

O perito médico, por ser responsável por delimitar a condição clínica da doença e os prejuízos ocasionados por ela, que afetem o trabalho do usuário, tem maior poder de decisão na determinação da elegibilidade do trabalhador para o PRP; o Responsável pela Orientação Profissional atua como um coadjuvante nessa decisão, o que compromete a avaliação no que tange a outros aspectos que deveriam ser igualmente relevantes, como os psicossociais, tão importantes quanto à avaliação clínica.

Não são avaliadas as questões sociopolíticas da incapacidade, uma vez que somente os agravantes físicos são considerados. Nesse sentido, um dos desafios a serem vencidos diz respeito à construção de um consenso sobre as concepções de saúde, incapacidade, reabilitação psicossocial e profissional (SIMONELLI et al., 2010; MAENO; VILELA, 2010).

Tradicionalmente, o profissional sobre quem recai a responsabilidade de avaliar a incapacidade é o médico; sua formação é focada no raciocínio clínico, na realização diagnóstica, seguindo critérios pessoais e, com frequência, descontextualizados. Os critérios passam a sofrer influências, explícitas e implícitas, da instituição a qual se vincula o profissional, das normas e regras de conduta, com um raciocínio baseado no deferimento ou indeferimento de um pleito do contribuinte (MAENO; VILELA, 2010).

De forma abstrata e solitária, o perito médico é quem define a concessão do benefício ao trabalhador e seu futuro profissional. As limitações do trabalhador são vistas a partir de uma avaliação parcial da incapacidade, sem considerar a relação homem-trabalho ao se pensar no retorno do usuário ao seu local de trabalho, ou seja, a interação entre os diversos aspectos da disfunção apresentada, dos atributos da pessoa e do contexto ambiental e de trabalho onde ela está inserida (SIMONELLI et al., 2010).

Os métodos de trabalho dos serviços de reabilitação profissional perpassam a focalização da clientela, elegendo de forma seletiva os grupos a serem atendidos. O sistema de proteção social ao trabalhador brasileiro, longe de ser universalista, é seletivo, insuficiente e precário, com base em critérios de mérito, numa lógica de benemerência. Os trabalhadores, assalariados, encontram-se estratificados e atomizados, dependentes de forças e decisões que estão fora de seu controle, inseguros, o que diminui sua capacidade de mobilização (TAKAHASHI; CANESQUI, 2003; YAZBEK, 2012; ESPING-ANDERSEN, 1991). 
A seguir, nos deteremos em cada uma das categorias que englobam o conjunto de motivos para que o trabalhador não seja atendido pelo PRP.

\section{Possibilidade de Retorno ao Trabalho}

A primeira categoria, "Possibilidade de Retorno ao Trabalho", principal motivo para a não inclusão dos trabalhadores no Programa, totalizou quase metade das negativas descritas pelos profissionais da equipe, com $46,97 \%$. Significa que o trabalhador foi considerado apto para retornar ao trabalho de origem.

Essa categoria abrange basicamente todas as pessoas que: a) possuíam condições de desempenhar a função de origem, pois não apresentavam limitação funcional no exame físico, e as sequelas eram compatíveis com a atividade laboral declarada; b) aquelas que tinham qualificação ou experiências profissionais anteriores compatíveis com o potencial laborativo residual; c) as que não apresentaram documentos médicos ou não estavam em tratamento médico; d) as que foram julgadas com sinais de estarem trabalhando.

Evidencia-se, em parte das justificativas, a desconfiança quanto à veracidade das limitações laborativas apresentadas pelo trabalhador. Este é avaliado minuciosamente com relação às possíveis fraudes no que tange ao acesso aos benefícios previstos, sendo, em alguns casos, apontado no laudo final em que restou claro o exercício de atividade laborativa durante o gozo do benefício.

A ausência de critérios técnicos na avaliação do potencial laborativo do usuário encaminhado ao PRP impõe dificuldades insuperáveis aos peritos médicos na realização de seu trabalho. Responsáveis solitários por este papel utilizam como "ferramenta operacional a busca insana por segurados simuladores, aqueles que não estariam socialmente legitimados a não trabalhar, em última análise, fraudadores do sistema de seguro social" (MAENO; TAKAHASHI; LIMA, 2009, p. 56).

Segundo Castel (2010, p. 67), a assistência prestada aos indivíduos no campo social tinha como critério a teoria da desvantagem, assim, "o pobre mais digno de mobilizar a caridade é o que exibe em seu corpo a impotência e o sofrimento humanos". A incapacidade física, as doenças, de preferência insuportáveis ao se olhar, sempre foram a melhor via para se tornar um assistido, uma lógica de assistência observada até hoje.

A pesquisa que serviu de base para este estudo apontou que 78,21\% dos usuários encaminhados ao Programa recebiam até três salários-mínimos, uma renda muito baixa para suprir as necessidades básicas de uma família, por vezes aquém, de forma significativa, do rendimento do trabalhador em atividade. Pode-se, portanto, supor que trabalhar ou fazer "bicos", durante o período de recebimento do benefício, pode significar a sobrevivência dos contribuintes, que se veem obrigados a fazê-lo, mesmo doentes ou com importantes incapacidades laborativas, para suprir suas necessidades básicas.

Conforme estudo realizado por Bernardo (2006), os "bicos" eventuais durante o afastamento, para os trabalhadores em PRP de uma Agência do INSS, que conseguiam desempenhar atividades laborativas, mesmo com limitações, representavam uma complementação do benefício previdenciário, porém dependiam em grande parte de contatos familiares e pessoais para ter acesso aos "bicos".

Fica claro, numa das justificativas para não eleger o trabalhador, que ele é apontado como responsável, individualmente, por suas incapacidades e, além disso, julgado capaz de sozinho buscar nova função compatível com o potencial laborativo residual. Não se lida com aquilo que é declarado como tarefa do Programa, justamente tomar como responsabilidade do poder público a reabilitação profissional desses sujeitos, e não delegar que eles, sozinhos, encontrem recursos para traçar um novo caminho profissional.

Na delimitação da condição laboral do usuário, é necessária uma visão do contexto como um todo, das queixas do trabalhador, do trabalho real ao invés do enfoque no prescrito, das condições organizacionais e sociopolíticas. Para Takahashi e Canesqui (2003), a intervenção da equipe também deve considerar as limitações em outras dimensões, tais como a emocional, social e relacional, com vistas a resgatar a autonomia dos adoecidos não somente para o trabalho, mas para a vida em geral.

Para que os trabalhadores possam galgar postos de trabalho melhores e se mantenham em empregos formais, a qualificação constante é essencial, a fim de que não se somem à massa de "desqualificados" e desempregados, devendo ser o ingresso no Programa um recurso do contribuinte adoecido na complementação de sua qualificação.

Há, de um lado, em escala minoritária, trabalhadores mais qualificados, multifuncionais e polivalentes, capazes de operar máquinas e exercitar de forma mais intensa sua dimensão intelectual e, de outro, uma massa de trabalhadores precarizados, que não possuem qualificação e vivenciam formas de trabalho precárias, temporárias, parciais ou o desemprego, à margem do processo produtivo (ANTUNES, 2011).

A não inclusão do trabalhador por ser considerado apto para retornar ao trabalho pode indicar, ainda, encaminhamentos incorretos, ou simbolizar o receio do perito médico que realizou o encaminhamento ao Pro- 
grama, em cessar o benefício do indivíduo. A cessação do benefício implica uma exposição do profissional que o fez, inclusive pessoal, e o órgão não se responsabiliza pela segurança dos servidores.

Há de se refletir também sobre o fato, conforme estudo de Bernardo (2006) com relação aos significados do trabalho e da reabilitação profissional para o trabalhador incapacitado, de que, para as pessoas que vivenciaram longos períodos de afastamento, ocorre uma ruptura com as condições formais de trabalho, e voltar a uma atividade laborativa formal não é uma expectativa.

\section{Impossibilidade de Retorno ao Trabalho}

Essa categoria teve uma incidência de $29,55 \%$ e foi a segunda causa relatada pelos profissionais, nos prontuários, de inelegibilidade para integrar o PRP. Na maioria desses casos, pontuou-se que foi sugerida a aposentadoria por invalidez do trabalhador, uma vez que este foi considerado com baixo potencial laborativo residual e, mesmo se fosse reabilitado, não teria condições de enfrentar o mercado de trabalho e pleitear uma vaga de emprego. Nos laudos, havia no mínimo três das justificativas discriminadas na sequência, associadas, ou seja, elas não apareceram isoladas em nenhum caso.

As explicações dadas abrangeram sobretudo o fato de o trabalhador: a) possuir baixa escolaridade ou ser analfabeto e, desse modo, não seria possível sua matrícula em cursos de qualificação; b) ter idade avançada, na medida em que foi considerado o período necessário para a elevação de escolaridade somado ao tempo que seria gasto na realização de um curso de qualificação e, como seriam precisos muitos anos para tanto, haveria dificuldades no retorno ao trabalho; c) possuir repertório profissional restrito, principalmente, às atividades braçais, o que significava que a pessoa não tinha experiências de trabalho em outras áreas que permitissem a reabilitação; d) residir em cidade distante da sede do Programa, pois haveria dificuldade, ou seria inviável o deslocamento do usuário para realizar cursos de qualificação, os quais são oferecidos somente no município sede do Programa; e) residir em cidade de pequeno porte, o que implicaria poucos postos de trabalho, em áreas restritas, dificultando o reingresso no mercado de trabalho formal.

Além desses motivos, também foram apontados: o fato de o trabalhador ter muitos anos de contribuição ao INSS, o que, somado a outros fatores, daria subsídios para a sugestão de aposentadoria por invalidez; diagnóstico ou limitação importante, progressiva, de difícil reinserção no mercado de trabalho; muitos anos exercendo a mesma profissão; valor alto do benefício ou do último salário, uma vez que, caso o usuário fosse reabilitado, o rendimento salarial na nova área seria inferior ao que ele recebia antes do ingresso no Programa; estar em gozo de benefício considerado longo, sem melhoras no quadro clínico, durante o afastamento.

A sugestão de aposentadoria por invalidez pode apontar o Programa como o último recurso na tentativa de retorno do contribuinte ao trabalho, ou um meio de embasar a sugestão de uma aposentadoria, no caso do sujeito ser inelegível

Tendo conhecimento e se apropriando de seus direitos e deveres, os trabalhadores podem cobrar pelo encaminhamento devido e pela inclusão no Programa, com uma participação ativa, se julgarem que este lhes traria alguma contribuição. Poderiam também cobrar melhorias desse aparato que, até aqui, não se tornou um aliado efetivo do trabalhador brasileiro. para o PRP. Pode representar encaminhamentos tardios que, se fossem realizados antes, aumentariam as chances de inclusão no Programa e de retorno ao trabalho.

Em outros casos, referentes aos encaminhamentos tardios, a pessoa fica afastada por vários anos, aguardando uma cirurgia no Sistema Único de Saúde (SUS); caso essa fosse realizada no momento certo e o mais precocemente possível, o sujeito poderia retornar ao trabalho de origem, ou não ficaria com sequelas estritamente incapacitantes, tornando-se elegível para o PRP.

A reformulação do modelo previdenciário de reabilitação profissional, com a supressão das atividades terapêuticas, que passaram a ser de responsabilidade do SUS, repercutiu na atenção à saúde do trabalhador; a desassistência nesta área acarreta a necessidade de prolongamento do tempo de afastamento do trabalho do contribuinte, pela permanência da incapacidade. Consequentemente, há um aumento do grau de desvantagem das pessoas adoecidas e acidentadas, influenciando no retorno ao trabalho (TAKAHASHI et al., 2010). 
A baixa escolaridade representa um fator determinante para o ingresso no Programa. Dados do estudo demonstraram que cerca de $42 \%$ dos trabalhadores encaminhados à reabilitação não concluíram o Ensino Fundamental, ou seja, suas chances de ser readaptado na empresa de vínculo ou ser qualificado são pequenas. Cada vez mais os postos de trabalho exigem um maior nível de escolaridade, sendo o Ensino Fundamental completo o mínimo para ingresso em cursos de qualificação, que são oferecidos pelo Programa por meio de uma rede de escolas conveniadas.

O nível de escolaridade dos usuários do Programa é muito baixo; para o exercício de algumas profissões, há alguns anos, não era exigida uma boa escolaridade, sendo contratadas pessoas na condição de analfabetas funcionais, características presentes nos usuários do Programa (VACARO; PEDROSO, 2011). Em estudo da década de 1980, que toma como referência a Alemanha, Offe (1984) discute que a relação escolaridade/postos de trabalho vem sendo ampliada, independentemente do que a tarefa efetivamente exija.

Para Castel (2010), promover a melhoria das condições de escolarização e de formação de uma população, cuja ausência de qualificação, mais do que a falta do trabalho, a torna não empregável, representa uma possibilidade de, pelo menos, igualá-la ao mesmo nível das oportunidades que poderão ser abertas. Estas são condições necessárias, mas não suficientes. A elevação do nível de formação deve continuar sendo um objetivo social, mas nem todo mundo é qualificado e competente; é preciso considerar, ainda, como um problema, a possível não empregabilidade das pessoas qualificadas.

A idade mais avançada e as limitações laborativas graves representam um perfil de pessoa com chances pequenas de contratação num emprego formal. As pessoas com limitações laborativas mais graves podem exigir maior flexibilidade na produção e adaptação dos postos de trabalho da empresa, além daquelas com idade mais avançada e com alguma limitação representarem um perfil que o mercado não tem interesse em absorver.

O fato de o usuário residir em cidade distante da sede do Programa demonstra a necessidade de o órgão ampliá-lo para todas as Agências do INSS, com a fixação de equipes em todas elas; assim, seria possível abarcar um maior número de trabalhadores na reabilitação profissional. Também, a necessidade de ampliar os convênios com as escolas que ofertam os cursos significaria poder qualificar o usuário em seu local de residência, evitando deslocamentos inviáveis e baixa adesão ao Programa.

Pessoas com repertório profissional restrito, sem experiências de trabalho em outras áreas que permitissem a reabilitação e com vínculos curtos de trabalho, não foram incluídas no Programa. É importante lidar com um histórico profissional anterior ao afastamento que permita retomar ou recriar a construção de um outro percurso profissional.

Para os reabilitandos que são encaminhados para a escolha de curso, busca-se, em conjunto com o trabalhador, o melhor caminho a ser seguido, com base em seu repertório profissional e seus interesses. A preparação para uma nova profissão é um grande desafio para os reabilitandos e para a equipe, pois envolve instrumentalizar o usuário para gerar o seu sustento, numa direção diferente da qual está habituado, e ainda tendo que conviver com perdas na sua capacidade laborativa (BREGALDA; LOPES, 2011).

Alguns dos usuários envolvidos nesta pesquisa estavam exercendo há muitos anos a mesma profissão, ponto importante a ser considerado pela equipe. Bernardo (2006) expõe que quase todos os trabalhadores entrevistados em sua pesquisa (usuários do PRP) expuseram que têm uma sensação afetiva, nostálgica, com o trabalho que exerciam antes do afastamento. Bregalda e Lopes (2011) complementam que, para aqueles que possuem uma história profissional que constitui parte de sua identidade e da qual se orgulham, é muito difícil promover o retorno aos estudos e o encaminhamento para aprender outra atividade.

Os dados permitem afirmar que vários pontos considerados pela equipe no momento da APL para sugerir a aposentadoria por invalidez são válidos, pois, realmente, poderiam prejudicar de forma significativa a reinserção do trabalhador no mercado, caso fossem elegíveis para o PRP. Entretanto, ressalta-se que a participação do trabalhador nessa decisão deve ser uma prerrogativa a ser seguida, na medida em que a aposentadoria por invalidez é uma decisão extrema e que pode acarretar prejuízos ao trabalhador.

\section{Potencial Laborativo Indefinido}

Verificado em $15,15 \%$ dos casos, essa justificativa se refere àqueles sujeitos que estavam com o quadro clínico não estabilizado, em tratamento médico, ou aguardando procedimento cirúrgico, e, assim, não era possível delimitar o potencial laborativo. Foi apontado pela equipe do Programa que: alguns trabalhadores não tinham diagnóstico definido, já que estavam em processo de investigação clínica; outros aguardavam cirurgia e, após o tratamento e realização desta, poderiam apresentar ganho funcional e retornar à função de origem, ainda que com atividades modificadas; alguns estavam com sintomatologia 
ativa e apresentavam limitações ao exame físico; houve agravamento do quadro clínico; outros estavam em ajuste de medicação e definição do plano terapêutico.

Nesses casos, ou o trabalhador poderia retornar, após a estabilização do quadro clínico, à função de origem, ou então seria um caso potencial para ingresso no Programa posteriormente. Conforme Simonelli et al. (2010), como no Brasil o PRP do INSS não se responsabiliza pela reabilitação física do trabalhador, cabendo ao SUS essa etapa, é necessário que o encaminhamento ao Programa ocorra quando o usuário estiver estabilizado quanto a isso.

\section{Inelegível Temporário}

Categoria descrita em 4,55\% dos prontuários refere-se à impossibilidade, no momento em que foi feita a avaliação, de inclusão do trabalhador no Programa. Em todos os casos, foi sugerida pelo perito médico revisão do benefício após dois anos, conhecido como R2, ou seja, foi proposto que o sujeito ficasse afastado do trabalho, recebendo o benefício da Previdência, por dois anos consecutivos para, nesse período, na maior parte dos casos, o trabalhador elevar a escolaridade, após o que, poderia ser reencaminhado e tornar-se elegível para o PRP.

Tais usuários correspondem a um perfil majoritário de pessoas com baixa escolaridade e, provavelmente, para não se elevar a meta do tempo de permanência do usuário no Programa, de 240 dias² $^{2}$ é sugerido o afastamento de dois anos. É uma saída não oficial, encontrada pela equipe da Agência pesquisada, na tentativa de solucionar um dos maiores empecilhos para a reabilitação profissional, que é o nível de escolaridade dos usuários do serviço. Por um lado, pode não sobrecarregar o Programa, por outro, o tempo de afastamento do trabalho continuará o mesmo, longo.

Abreu e Ribeiro (2010) detectaram que os usuários com menor nível de escolaridade eram aqueles que apresentavam maior tempo de afastamento. Vacaro e Pedroso (2011) chegaram à mesma conclusão, acrescida do fato de que, quanto maior o tempo em benefício, menor o sucesso do Programa de Reabilitação Profissional. A necessidade de elevação do nível escolar é explícita para o ingresso nos cursos de qualificação oferecidos, os quais exigem um mínimo que os usuários, majoritariamente, não têm.

Acredita-se que a não inclusão no Programa de pessoas com baixa escolaridade e a concessão de um tempo de dois anos de afastamento para que elas consigam melhorá-la não são garantias de adesão à proposta nem de sucesso futuro no Programa, isto se o usuário for realmente reencaminhado ao PRP. Muitos referem como sendo penoso e difícil esse processo de "volta à escola", uma vez que permaneceram, na maior parte dos casos, longos anos sem estudar; sem o acompanhamento de uma equipe especializada, que ofereça algum suporte a esse retorno, o sucesso dessa "manobra" pode ser nulo ou muito baixo, sendo mais viável eleger o trabalhador para a reabilitação profissional e nela trabalhar a elevação de sua escolaridade.

\section{Transferência do Benefício}

Apontada como justificativa para a não inclusão de 2,27\% dos usuários avaliados, isto basicamente diz respeito àqueles em que a pessoa, depois de ser encaminhada ao Programa, solicitou a transferência do benefício para outra Agência da Previdência Social (não abrangida pela Agência estudada), ou também aos sujeitos que residiam em cidade distante ou em outro estado (igualmente, não pertencente à área de atenção da Agência em tela), e foram orientados pelos profissionais a efetuarem a transferência do benefício para a Agência mais próxima de sua residência.

Os casos de transferência do benefício aparecem porque o agendamento de perícia médica pode ser feito em qualquer Agência do INSS, no Brasil todo. Dessa forma, caso a perícia e o encaminhamento ao Programa tenha ocorrido em local distante da residência do sujeito, é preciso realizar tal transferência. Cada Gerência do INSS que conta com o PRP tem uma área de abrangência para os atendimentos de pessoas moradoras daquela região. No entanto, para que isso ocorra, é preciso também que o benefício seja mantido por uma Agência pertencente àquela Gerência.

Em muitos casos, o contribuinte agenda uma perícia em trânsito, no local em que ocorreu o acidente, ou é a empresa que faz o agendamento, na Agência mais próxima da sua sede. Pode ocorrer que trabalhadores, migrantes, retornem para seu estado natal após adoecerem ou se acidentarem, o que também inviabiliza o atendimento, ou simplesmente se mudarem para outra cidade não abrangida pela Agência que mantém seu benefício. A realização da avaliação para o Programa no local mais próximo de onde resida o trabalhador implica uma possibilidade maior de sucesso no processo de reabilitação profissional. 


\section{Trabalhador Autorreabilitando}

A expressão autorreabilitando apareceu em $1,14 \%$ dos laudos descritivos, relacionada pela equipe aos trabalhadores que, por conta própria, se engajaram em outras atividades laborativas, durante o afastamento, compatíveis com seu potencial laborativo residual. Em um dos casos, o sujeito elevou a categoria da Carteira Nacional de Habilitação $(\mathrm{CNH})$ para exercer atividades na área; em outro, a pessoa já havia conseguido emprego em vaga adequada às suas limitações; por fim, um deles estava trabalhando em casa, também em área considerada compatível.

Pode significar que esses trabalhadores permaneciam em período longo de afastamento e/ou foram encaminhados tardiamente ao Programa, sendo assim, organizaram-se, por conta própria, na busca por atividades laborativas adequadas ao seu potencial laborativo residual ou adaptação das atividades de origem. Esse fato indica falhas de encaminhamentos de casos potenciais a serem reabilitados profissionalmente, bem como a falta de responsabilização do órgão no engajamento desses usuários ao Programa. Por outro lado, Takahashi et al. (2010) inferiram que alguns trabalhadores podem desenvolver recursos próprios, adaptativos, que não demandam um programa de reabilitação profissional.

\section{Considerações finais}

Apesar das várias críticas voltadas ao Programa de Reabilitação Profissional do INSS, não ter a possibilidade de ser eleito e atendido para, ao menos, uma tentativa de reabilitação, acarretando a manutenção do recebimento do benefício por mais tempo, significa suprimir o direito de vários usuários, que contribuem com a Previdência, financiando essa proteção ao trabalhador no Brasil. Estes, quando se deparam com a necessidade de acessar os benefícios previdenciários, ficam submetidos à avaliação da perícia médica ou da equipe ${ }^{3}$ do Programa e ao seu poder de decisão. São os profissionais que definem quem terá direito, ou não, aos benefícios, e por quanto tempo, seguindo critérios próprios e heterogêneos, de modo absolutamente verticalizado, em que não se tem o envolvimento efetivo do trabalhador na definição do melhor (ou do menos ruim) a ser feito nesse momento difícil de sua vida.

Uma melhor apreensão do Programa entre os profissionais do INSS e entre os trabalhadores e empresas poderia evitar muitos encaminhamentos precoces ou tardios, que inviabilizam a elegibilidade do usuário para ser atendido pelo Programa. Tendo conhecimento e se apropriando de seus direitos e deveres, os trabalhadores podem cobrar pelo encaminhamento devido e pela inclusão no Programa, com uma participação ativa, se julgarem que este lhes traria alguma contribuição. Poderiam também cobrar melhorias desse aparato que, até aqui, não se tornou um aliado efetivo do trabalhador brasileiro.

A reabilitação profissional poderia se estabelecer como um recurso público no auxílio a todos os trabalhadores adoecidos e incapacitados para o exercício de sua profissão habitual. Além disso, poderia se transformar efetivamente em "cuidado", acolhimento e atenção aos sujeitos e não se manter como um Programa que prevê que o trabalhador deve se submeter e cumprir o processo reabilitatório, condição necessária para o recebimento do benefício previdenciário (BRASIL, 2010b), em uma lógica punitiva, às vezes contrária aos interesses do trabalhador.

$\mathrm{O}$ acesso ao sistema previdenciário e aos seus benefícios, como mostra a literatura, é privilégio de algumas categorias de trabalhadores e, ainda assim, mesmo fazendo parte desse seleto grupo, os contribuintes não conseguem usufruir daquilo que a reabilitação profissional pode prover. São inúmeros os obstáculos, desde a entrada no sistema, no longo caminho para o reconhecimento de direitos do trabalhador e acesso aos bens sociais deles advindos no Brasil.

\section{Referências}

ANTUNES, R. Adeus ao trabalho? Ensaio sobre as metamorfoses e a centralidade no mundo do trabalho. 15a Edição, São Paulo: Cortez, 2011. ABREU, A. T. J. B.; RIBEIRO, C. A. B. Prevalência de lombalgia em trabalhadores submetidos ao Programa de Reabilitação Profissional do Instituto Nacional do Seguro Social (INSS), São Luís, MA. Acta Fisiatr., v. 17, n. 4, p.148-152, 2010.

BERNARDO, L. D. Os significados do trabalho e da reabilitação profissional para o trabalhador incapacitado para o exercício da profissão habitual. 102 p. Dissertação (Mestrado em Saúde Pública) - Faculdade de Medicina, Universidade Federal de Minas Gerais, Belo Horizonte, 2006.

BRASIL. Decreto n ${ }^{\circ}$ 3.048, de 06 de Maio de 1999. Capítulo V: Da Habilitação e da Reabilitação Profissional. Diário Oficial da República Federativa do Brasil, Poder Executivo, Brasília, DF, 07 Maio 1999, atualizado jan. 2010a. 
Instituto Nacional do Seguro Social. Instrução Normativa No 45/INSS/PRES, de 06 de Agosto de 2010. Dispõe sobre a administração de informações dos segurados, o reconhecimento, a manutenção e a revisão de direitos dos beneficiários da Previdência Social e disciplina o processo administrativo previdenciário no âmbito do Instituto Nacional do Seguro Social. Diário Oficial da República Federativa do Brasil, n. 153, Poder Executivo, Brasília, DF, 11 ago. 2010 b.

. Instituto Nacional do Seguro Social. Despacho Decisório No2/DIRSAT/INSS, 24 Nov. 2011. Manual Técnico de Procedimentos da Área de Reabilitação Profissional. Diretoria de Saúde do Trabalhador - DIRSAT, nov. 2011.

BREGALDA, M. M.; LOPES, R. E. O Programa de Reabilitação Profissional do INSS: apontamentos iniciais a partir de uma experiência. Cadernos de Terapia Ocupacional da UFSCar, São Carlos, v. 19, n. 2, p.249-261, mai./ago., 2011.

CASTEL, R.. As metamorfoses da questão social: uma crônica do salário. $9^{a}$ Edição. Petrópolis: Vozes, 2010.

ESPING-ANDERSEN, G. As três economias políticas do Welfare State. Lua Nova, n. 24, p. 85-116, set., 1991.

GIL, A. C.. Método e técnicas de pesquisa social. São Paulo: Atlas, 1999.

LAKATOS, E. M.; MARCONI, M. A. Técnicas de pesquisa. São Paulo: Atlas, 2002.

MAENO, M.; TAKAHASHI, M. A. C.; LIMA, M. A. G. Reabilitação Profissional como política de inclusão social. Acta Fisiatr., v. 16, n. 2, p. 53-58, 2009.

MAENO, M.; VILELA, R. A. G. Reabilitação profissional no Brasil: elementos para a construção de uma política pública. Rev. Bras. Saúde Ocup., v. 35, n. 121, p.87- 99, 2010.

OFFE, C. Problemas estruturais do Estado capitalista. Rio de Janeiro: Tempo Brasileiro, 1984.

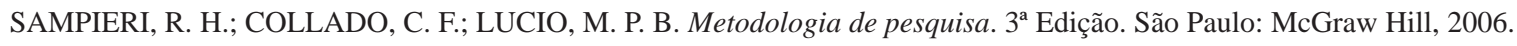

SIMONELLI, A. P. et al. Proposta de articulação entre abordagens metodológicas para melhoria do processo de reabilitação profissional. Rev. Bras. Saúde Ocup., São Paulo, v. 35, n. 121, p.64-73, 2010.

TAKAHASHI, M. A. B. C.; IGUTI, A. M. As mudanças nas práticas de reabilitação profissional da Previdência Social no Brasil: modernização ou enfraquecimento da proteção social? Cad. Saúde Pública, v. 24, n. 11, p.2661-2670, 2008.

TAKAHASHI, M. A. B. C. et al. Programa de reabilitação profissional para trabalhadores com incapacidades por LER/DORT: relato de experiência do Cerest-Piracicaba, SP. Rev. Bras. Saúde Ocup., São Paulo, v. 35, n. 121, p.100-111, 2010.

TAKAHASHI, M. A. C.; CANESQUI, A. M. Pesquisa avaliativa em reabilitação profissional: a efetividade de um serviço em desconstrução. Cad. Saúde Pública, Rio de Janeiro, v. 19, n. 5, p.1473-1483, set-out, 2003.

VACARO, J. E.; PEDROSO, F. S. Desempenho dos segurados no serviço de reabilitação do Instituto Nacional de Seguridade Social. Acta Fisiatr., v. 18, n. 4, p.200-205, 2011.

YAZBEK, M. C. Pobreza no Brasil contemporâneo e formas de seu enfrentamento. Serv. Soc. Soc., São Paulo, n. 110, p. 288-322, abr./ jun., 2012.

\section{Notas}

1 Este texto é parte dos resultados de uma pesquisa que compõe a dissertação de mestrado intitulada O Programa de Reabilitação Profissional do Instituto Nacional do Seguro Social e a Reinserção do Trabalhador no Mercado de Trabalho: Um Estudo de Caso, desenvolvida junto à linha de pesquisa Redes Sociais e Vulnerabilidade do Programa de Pós-Graduação em Terapia Ocupacional da Universidade Federal de São Carlos (UFSCar).

2 Atualmente, no Manual Técnico de Procedimentos da Área de Reabilitação Profissional do INSS, nãoé prevista claramente uma meta de tempo de permanência do usuário no Programa, porém, no BoletimEstatístico da Reabilitação Profissional (BERP), preenchido pela equipe mensalmente, é fiscalizada a quantidade de usuários em Programa por mais de 240 dias.

3 Aequipe do Programa de Reabilitação Profissional daAgência pesquisada contava apenas com um perito médico e dois terapeutas ocupacionais. Portanto, apesar da legislação pertinente prever o profissional da área de assistência social na composição das equipes, o que é primordial para a melhor consecução da atenção aos trabalhadores em processo de reabilitação profissional no INSS, isso não acontecia no caso em estudo.

\section{Geovana de Souza Henrique dos Santos}

geovana_shs@yahoo.com.br

Mestre em Terapia Ocupacional pela Universidade Federal de São Carlos (UFSCar)

Terapeuta Ocupacional no Instituto Nacional do Seguro Social (INSS)

\section{Roseli Esquerdo Lopes}

relopes@ufscar.br

Doutora em Educação pela Universidade Estadual de Campinas (UNICAMP)

Professora Titular do Departamento de Terapia Ocupacional da Universidade Federal de São Carlos (UFSCar) 
UFSCar - Laboratório METUIA do Departamento de Terapia Ocupacional da Universidade Federal de São Carlos

Rodovia Washington Luís, Km 235, s/n - Jardim Guanabara.

São Carlos - São Paulo - Brasil

CEP: $13565-905$ 